\title{
Requirements and Barriers for Introducing Smart Manufacturing in Small and Medium-Sized Enterprises
}

\section{-ERWIN RAUCH}

Industrial Engineering and Automation, Faculty of Science and Technology, Free University of Bolzano, 39100 Bolzano, Italy

\section{-PATRICK DAllasega}

Industrial Engineering and Automation, Faculty of Science and Technology, Free University of Bolzano, 39100 Bolzano, Italy

\section{- MARCO UNTERHOFER}

Industrial Engineering and Automation, Faculty of Science and Technology, Free University of Bolzano, 39100 Bolzano, Italy

(Corresponding author: Patrick Dallasega.)

IEEE DOI 10.1109/EMR.2019.2931564

\begin{abstract}
Bigger companies have been the main adopters of Industry 4.0. However, small- and medium sized enterprises (SMEs) are significant economic and employment contributors in the European Union and the United States. For a successful application of Industry 4.0, customized implementation strategies and approaches as well as adapted concepts and technological solutions are needed. The paper presents requirements and barriers for introducing smart manufacturing in SMEs. These items were identified throughout the research project "SME 4.0 - Industry 4.0 for SMEs" by using expert workshops with SMEs from the United States, Central Europe, and Northern Thailand. The results inform recommendations for managerial action to support an appropriate adaptation of Industry 4.0 technologies and concepts into SMEs.
\end{abstract}

Key words: Barriers, Industry 4.0, requirements, small and medium-sized enterprises, smart manufacturing

\section{INTRODUCTION}

NDUSTRY 4.0 aims at increasing digitization and automation of the manufacturing industry by merging information technology (IT) with production and logistics processes. Industry 4.0 has been mainly introduced by bigger companies and small- and medium sized enterprises (SMEs) are not fully able to exploit Industry 4.0's potential for efficiency improvements.

An investigation in how Industry 4.0 concepts and technologies can be appropriately applied to SMEs commenced ([Rauch et al., 2019]; [Dallasega et al., 2019]). Various governments have started to actively financially support SMEs in the adoption of Industry 4.0 - for example the European Commission and the Thai government.

Some studies reveal the potential for SMEs to apply Industry 4.0 to enhance their competitiveness [Rickmann, 2014]. Compared to larger companies, SMEs have the potential to more rapidly implement digital transformations; they typically have increased flexibility in terms of process and technology changes.

Industry 4.0 still represents a special challenge for businesses in general and for SMEs in particular. SMEs are not ready due to limited organizational capability to adapt Industry 4.0. In particular, compared with bigger companies, SMEs have usually fewer financial resources for research and development and less qualified staff [Matt et al., 2018].

SMEs are defined by the European Commission as having fewer than 250 employees and an annual turnover - revenue - of less than $€ 50$ million. They are considered the backbone of the European economy.

According to SME statistics from the 2015 Eurostat database in 2015, there were 23.4 million SMEs in the European Union's (EU) non-financial sector. Together they employed 91 million people and generated $€ 3,934$ billion of value. Large enterprises 
represent $0.2 \%$ of all enterprises in the EU and generate $43.5 \%$ of value. These large enterprises account for around one third of the number of employees (33.7\%).

Two-thirds of employees in the nonfinancial sector are employed by SMEs, with $29.1 \%$ in micro enterprises with less than 10 persons employed, $20.2 \%$ in small enterprises with less than 49 persons employed, and $17.1 \%$ in medium enterprises with less than 250 employees. All three sizes of SMEs are contributing nearly equally to value added in the EU with $20.3 \%$ for micro enterprises, $17.6 \%$ for small enterprises and $18.5 \%$ for mediumsized enterprises (Eurostat, 2018).

The economic contribution from SMEs is particularly apparent in Malta, Cyprus, Estonia, Greece, Latvia, Lithuania and Italy with SMEs providing more than two-thirds of the total value generated. In the overall $\mathrm{EU}$, the value added generated by SMEs is $56.5 \%$ (Eurostat, 2018).

The number of EU SMEs increased by $13.8 \%$ between 2008 and 2017 . SMEs represented $88.3 \%$ of all enterprises exporting goods. Most SMEs were engaged in intra-EU trade, while less than half of exporting SMEs sold to markets outside the EU [Brusselsnetwork, 2018].

Small to medium enterprises also make up the vast majority of businesses in the US. According to the U.S. Census Bureau Data from 2016, of the 5.6 million employer firms in the US, $99.7 \%$ had fewer than 500 employees, $98.2 \%$ had fewer than 100 employees and $89.0 \%$ had fewer than 20 employees.

SMEs contributed 46 percent of the private nonfarm GDP in 2008 - the most recent year for which the source data are available - making them important for economic growth, innovation, and diversity [Ward, 2018].
Small businesses in the US employed 58.9 million people, or $47.5 \%$ of the private workforce, in 2015. SMEs contribute to economic growth in the US as small businesses created 1.9 million net jobs in 2015 [SBA, 2018].

Given the importance of SMEs there is a need for further research and action plans to prepare SMEs for successful adoption and application of Industry 4.0. Successful application of Industry 4.0 to SMEs requires customized implementation strategies and approaches as well as adapted concepts and technological solutions. Otherwise, awarenessraising alone will not result in expected successful adoption.

We now delve into specific requirements, barriers and difficulties for introducing Industry 4.0 into SMEs. They were identified within the research project "SME 4.0 - Industry 4.0 for SMEs" by using expert workshops with SMEs from the Northeast part of the United States of America, Central Europe and Northern Thailand. We then provide insights for managers from these results.

\section{Methodology}

To obtain direct input from the beneficiaries of Industry 4.0 in manufacturing SMEs, we selected a primary research approach to collect specific user needs by interviewing SMEs. An explorative field study using SME workshops was used. These workshops allow for common exchange of experiences and to stimulate discussion among the participants, thus creating a deeper experiential environment.

Four SME workshops were held in Europe (Italy and Austria), the US (Massachusetts) and Asia (Thailand) to investigate specific requirements for SME. The implementation of SME workshops in different countries/ continents should also help to identify cultural or country-specific differences, thus avoiding local needs having a strong influence on the final design guidelines for the introduction of Industry 4.0 into SMEs.

The workshops had a standardized structure starting with an initial introduction and overview of Industry 4.0 , then presenting some practical applications and best practice examples in SMEs.

Afterwards, the participants were asked to express their needs and requirements for introducing Industry 4.0 concepts in their companies and share their experiences with the other participants.

They were then asked about the main barriers and limitations for the implementation of Industry 4.0. The inputs were collected in the form of sticky notes on pin boards and categorized by topic.

Before starting the evaluation of the collected inputs, several company visits were carried out at participating SMEs to gain a better practical understanding of the requirements and barriers.

Table 1 illustrates the structure of the workshops, where inputs were collected in three categories defined previously by the research team: (i) Smart Manufacturing, (ii) Smart Logistics (iii) Organization and Management Models for Smart SMEs. In this paper, we concentrate on the results obtained for the smart manufacturing category.

\section{REQUIREMENTS FOR SMART MANUFACTURING SYSTEMS IN SMES}

A total of 163 items with inputs from SME companies were collected in the workshops. These items were consolidated into 65 requirements indicated in Table 2 - for introducing 
smart manufacturing. Those 65 requirements are further subdivided into 27 Clusters.

From the requirements listed in Table 2, the following four requirements were of most interest to SME workshop participants:

1) Agility in manufacturing and Mass Customization: manufacturing systems need to be quickly adaptable, changeable and reconfigurable according to short-term changes in volume or product variant. This item allows for a profitable mass customization strategy.

2) Real-time data, digitization and connectivity: SMEs should work on vertical data integration from sales data in the ERP system over production planning and control tools to machine data on the shop floor level. Such integration is required to gain benefit from connecting machines and workstations and collecting their data in real-time. A challenge will be to convert legacy machines into "Industry 4.0 ready" ones, by installing loTgateways and sensors.

3) Advanced Manufacturing Technologies and Automation: with new emerging technologies on the market like high speed and high precision machines for milling and turning as well as with the introduction of collaborative robots. SMEs can take a further step towards automation although to produce small lot sizes.

4) Ease of Use and low Investment: when introducing new technologies in SMEs, they should be easy to learn and affordable for SMEs. An example is the use of robots in SMEs. Usually SMEs do not have highly qualified staff able to program robotic systems. Therefore, robotic systems for SMEs should be easy to handle and to program, as it is the case with most of the collaborative robots on the market.

The following topic is also of high interest for SMEs, although they are aware that they are not yet well prepared for these concepts:

1) Machine Learning and Smart Data Analytics: Machine Learning will become an important topic in the next few years for developing new and intelligent approaches for smart data analytics. Such data analytic tools can be used for both optimizing production planning and control strategies as well as to realize predictive maintenance in the shop floor.

\section{MAIN BARRIERS AND DIFFICULTIES}

The workshops also asked participants about difficulties they face. Thus an overview of the main limitations and barriers for smart manufacturing in SMEs was also determined. Table 3 summarizes the results showing 14 main limitations and barriers categorized into six Clusters.

From the limitations and barriers listed in Table 3 the following ones were discussed in detail during the workshops.

1) Cultural barriers in terms of lack of acceptance by the management and the operational level personnel were mentioned. Here, the lack of support by top management was highlighted, and confirmed by other studies (Orzes et al., 2019).

2) Considering the implementation phase, the frequent lack of experience in managing and applying Industry 4.0 concepts and technologies were mentioned. Specifically, the

\begin{tabular}{|lllll|}
\hline \multicolumn{5}{|c|}{ Table 1. Structure of SME Workshops } \\
\hline No. & Agenda point & Duration & Objective & Method \\
\hline 1 & Introduce project presentation & $15 \mathrm{~min}$ & $\begin{array}{l}\text { Explanation of the project and research } \\
\text { objectives }\end{array}$ & Opening presentation \\
\hline 2 & Concept and origin of Industry 4.0 & $30 \mathrm{~min}$ & $\begin{array}{l}\text { Introduction in Industry 4.0 for a com- } \\
\text { mon understanding }\end{array}$ & Opening presentation \\
\hline 3 & Best practice examples & $20 \mathrm{~min}$ & Awareness raising for implementation & Case studies, pictures, videos \\
\hline 4 & Overview methodology & $15 \mathrm{~min}$ & Understanding of the research method & Introductory presentation, examples \\
\hline 5 & Introduction brainstorming session & $10 \mathrm{~min}$ & $\begin{array}{l}\text { Understanding of the brainstorming } \\
\text { method }\end{array}$ & Introductory presentation \\
\hline 6 & Brainstorming 'Smart Manufacturing' & $90 \mathrm{~min}$ & $\begin{array}{l}\text { Creative brainstorming with sticky } \\
\text { notes and subsequent discussion }\end{array}$ & Sticky note method \\
\hline 7 & Brainstorming 'Smart Logistics' & $90 \mathrm{~min}$ & $\begin{array}{l}\text { Creative brainstorming with sticky } \\
\text { notes and subsequent discussion }\end{array}$ & Sticky note method \\
\hline 8 & $\begin{array}{l}\text { Brainstorming 'Organization and } \\
\text { Management Models for Smart SMEs' }\end{array}$ & $90 \mathrm{~min}$ & $\begin{array}{l}\text { Creative brainstorming with sticky } \\
\text { notes and subsequent discussion }\end{array}$ & Sticky note method \\
\hline 9 & Discussion and closure & $30 \mathrm{~min}$ & $\begin{array}{l}\text { Summary and impression of the day } \\
\text { Open discussion }\end{array}$ \\
\hline
\end{tabular}




\begin{tabular}{|c|c|c|}
\hline \multicolumn{3}{|r|}{ Table 2. Requirements for Introducing Smart Manufacturing in SMEs } \\
\hline Cluster & No & Requirements for the design of smart manufacturing systems in SMEs \\
\hline AGILITY & $\begin{array}{l}1 \\
2 \\
3 \\
4 \\
5 \\
5 \\
6\end{array}$ & $\begin{array}{l}\text { Build or improve production lines and work stations to be more compact } \\
\text { Ensure flexible, scalable, customizable production systems } \\
\text { Reduce set up time for new configurations } \\
\text { Produce a wide variety of products and at wide range of volumes without significant re-configuration costs, and } \\
\text { time } \\
\text { Adapt and adjust processes autonomously } \\
\text { Enable easy to use and change systems of new manufacturing technologies } \\
\text { Take advantage of rapid prototyping technologies to make product development easier, and reduce requirements } \\
\text { for stock }\end{array}$ \\
\hline AUTOMATION & $\begin{array}{l}8 \\
9 \\
10 \\
11\end{array}$ & $\begin{array}{l}\text { Mitigate repetitive tasks with quick payback time } \\
\text { Customize packaging on demand } \\
\text { Reduce labor and cost of all production and logistics processes } \\
\text { Implement self-maintaining processes }\end{array}$ \\
\hline CONNECTIVITY & $\begin{array}{l}12 \\
13 \\
14 \\
15\end{array}$ & $\begin{array}{l}\text { Ensure the ability to easily and efficiently communicate on a sufficiently real time basis with internal and external } \\
\text { customers } \\
\text { Standardize and simplify security and interoperability of information and communication technologies } \\
\text { Create standardized easy to use systems for connectivity, communication, and transparency } \\
\text { Enable internal and external information connectivity to enable better forecasting, inventory management, } \\
\text { current demand measuring, internal material requirements, etc. }\end{array}$ \\
\hline CULTURE & 16 & Understand the culture of customers to interpret preferences for cost and quality \\
\hline $\begin{array}{l}\text { DESIGN FOR } \\
\text { MANUFACTURING }\end{array}$ & 17 & Enable the use of advanced manufacturing technologies in the design phase \\
\hline DIGITIZATION & $\begin{array}{l}18 \\
19 \\
20 \\
21 \\
22 \\
23 \\
24\end{array}$ & $\begin{array}{l}\text { Implement automation and digitization of internal workflows and report generation } \\
\text { Reduce cost of physical prototyping } \\
\text { Implement clear data gathering, management, analysis, and visualization to both internal and external customers } \\
\text { Collect real-time data of machines, warehouses and facilities to keep production under control } \\
\text { Enable data flow has to be consistent through the whole product life cycle and in the whole supply chain } \\
\text { Enable fast measurement on-site and immediate delivery of data to production facility } \\
\text { Provide and visualize information everywhere and every time to reduce waiting times and unnecessary delays }\end{array}$ \\
\hline EASE OF USE & $\begin{array}{l}25 \\
26 \\
27\end{array}$ & $\begin{array}{l}\text { Simplify maintenance of newly adopted manufacturing technologies } \\
\text { Lower informational barrier, complexity of entry to new manufacturing technologies } \\
\text { Enable user-friendly robot programming for "normal" workers }\end{array}$ \\
\hline IMPLEMENTATION & $\begin{array}{l}28 \\
29 \\
30 \\
31\end{array}$ & $\begin{array}{l}\text { Manage legal and bureaucratic hurdles for introducing } 14.0 \text { technologies } \\
\text { Measure the impact of } 14.0 \text { on the company's sustainable success } \\
\text { Provide an overview of existing } 14.0 \text { instruments and their suitability for SMEs or industry sectors } \\
\text { Gain access to knowledge needed to implement } 14.0\end{array}$ \\
\hline INSPECTION & $\begin{array}{l}32 \\
33 \\
34\end{array}$ & $\begin{array}{l}\text { Identify a defect as early as possible with little to no worker intervention needed } \\
\text { Mitigate the human element in otherwise tedious or low information content tasks, such as delicate maintenance, } \\
\text { equipment calibration, etc. } \\
\text { Identify defects through in line inspection of process and material to avoid non-quality at the customer side }\end{array}$ \\
\hline LEAN & $\begin{array}{l}35 \\
36 \\
37\end{array}$ & $\begin{array}{l}\text { Reduce non-value adding activities in production and logistics } \\
\text { Produce on demand and deliver just in time } \\
\text { Move product individualization as late as possible in the value chain }\end{array}$ \\
\hline MACHINE LEARNING & & $\begin{array}{l}\text { Automatically identify and adjust parameter deviations in the manufacturing process influenced by environmental } \\
\text { variance } \\
\text { Implement fast and automated design-based generation of tool path, part processing plan and quotation }\end{array}$ \\
\hline MASS CUSTOMIZATION & 40 & Gain the ability to produce small lot sizes (lot size 1) without losing efficiency \\
\hline NETWORK & 41 & $\begin{array}{l}\text { Ensure that SME has a culture which includes the needs of the customer and workers through discourse and com- } \\
\text { munication to enable full and productive integration of SME } 4.0 \\
\text { Communicate and/or share capacity, materials, infrastructure, and information with internal and external custom- } \\
\text { ers, and suppliers }\end{array}$ \\
\hline PEOPLE & $\begin{array}{l}43 \\
44\end{array}$ & $\begin{array}{l}\text { Enable ergonomic support for physically difficult tasks } \\
\text { Manage internal knowledge and staff development for Industry } 4.0\end{array}$ \\
\hline $\begin{array}{l}\text { PRODUCTION PLANNING } \\
\text { AND CONTROL }\end{array}$ & 45 & $\begin{array}{l}\text { Enable a decentralized and highly reactive production planning and control } \\
\text { Forecast demand changes quickly and interact with systems for planning, control, and logistics }\end{array}$ \\
\hline $\begin{array}{l}\text { PREVENTIVE AND } \\
\text { PREDICTIVE } \\
\text { MAINTENANCE }\end{array}$ & $\begin{array}{l}48 \\
49\end{array}$ & $\begin{array}{l}\text { Proactively maintain to ensure availability and decrease down time of machines. } \\
\text { Predict data-based probability of machine stops or machine down time }\end{array}$ \\
\hline REAL TIME STATUS & 50 & $\begin{array}{l}\text { Digitize feedback system, and infrastructure, which monitors status of production, storage, shipping, risk, and cri- } \\
\text { sis management } \\
\text { Gather real-time status and visualize this data for operators and management }\end{array}$ \\
\hline REMOTE CONTROL & 52 & Enable location independent control of maintenance, facilities and products \\
\hline
\end{tabular}




\begin{tabular}{|lcl|}
\hline & \multicolumn{1}{c|}{ Table 2. (Continued) } \\
\hline Cluster & No & Requirements for the design of smart manufacturing systems in SMEs \\
\hline \multirow{2}{*}{ RESOURCE MANAGEMENT } & 53 & Monitor (data driven) material and process capability for all relevant resources \\
& 54 & Ensure machines are capable for prospective jobs, and are able to be repurposed for a variety of other jobs \\
& 55 & Reduce time investment for I4.0 implementation and throughout life cycle \\
\hline \multirow{2}{*}{ SAFETY } & 56 & Provide workers with ergonomic workplace \\
& 57 & Provide safe working environment \\
\hline \multirow{2}{*}{ SUSTAINABILITY } & 58 & Reduce energy consumption and environmental cost \\
& 59 & Measure and optimize energy, material, and time usage on processes \\
\hline \multirow{2}{*}{ TRACKING AND TRACING } & 60 & Track products easily from origin through the value chain \\
& 61 & Trace and locate products digitally along the supply chain \\
\hline TRANSPORT & 62 & Transport material inside the plant easily and without the need of a worker \\
\hline UPGRADE & 63 & Reuse and upgrade of existing manufacturing equipment \\
\hline \multirow{2}{*}{ VIRTUAL REALITY } & 64 & Allow user friendly 'smart' representation of systems for production, maintenance, design, and service \\
& 65 & Digitize product development, improvement, management and security to ensure product is more profitable for \\
& & SME and customer through product life \\
\hline
\end{tabular}

difficulties in budgeting because of a lack of experience were highlighted. The uncertain return of investment because of the unclear market potential of Industry 4.0 and the relatively long implementation process were also mentioned (Orzes et al. 2019).

3) The scarcity of qualified staff in SMEs, is an important barrier to successful adaptation and application of Industry 4.0; this concern was a core issue mentioned several times.

4) Workshop participants argued that their industrial facilities - buildings and infrastructure were not designed for automating internal transports or processes or to host new manufacturing technologies.

5) Finally, data security was mentioned as a very important aspect, which if not assured properly is one of the principal factors that decreases the acceptance level of Industry 4.0 by top management.

\section{IMPLICATIONS FOR MANAGERS}

A number of recommendations and implications for SMEs and their management teams exist. We summarize some of these now.

In the short term, SMEs should already try to advance digitization in the basics of everyday organizational life and start with simple activities such as paperless production. This can already be achieved with very cost-effective digital tools and devices - smartphones and tablets.

In the medium term, it is important to introduce connectivity in the shop floor. This means starting with a comprehensive enterprise resource planning (ERP) system. Machines and workstations can be connected

\begin{tabular}{|c|c|c|}
\hline 1 & & Lack of cooperation, openness and trust between firms \\
\hline 3 & CULTURE & $\begin{array}{l}\text { Company needs a well-entrenched top down culture which allows continual improvement and mitigation of silo } \\
\text { syndrome }\end{array}$ \\
\hline 4 & & $\begin{array}{l}\text { Regulations and culture of the sphere within which the SME and parent organization functions must be such that } \\
\text { proliferation of } 14.0 \text { is enabled, rather than disabled }\end{array}$ \\
\hline 6 & IMPLEMENTATION & Lack of experience in project management and budgeting for implementation of 14.0 \\
\hline 7 & PEOPLE & $\begin{array}{l}\text { Lack of training and qualification of personnel for systems to encourage communication, flexibility, education of } \\
14.0 \text { and soft skills } \\
\text { SMEs lack access to the financial, informational, digital, physical, and educational resources to ensure } 14.0 \text { is fully } \\
\text { realized. }\end{array}$ \\
\hline $\begin{array}{l}9 \\
10 \\
11\end{array}$ & RESOURCE MANAGEMENT & $\begin{array}{l}\text { Lack of easy access to thought leaders and talent (relative to multinational companies) } \\
\text { Buildings are not designed for automating internal transports or processes or for new manufacturing technologies } \\
\text { High financial barrier to new manufacturing technologies }\end{array}$ \\
\hline $\begin{array}{l}13 \\
14\end{array}$ & STRATEGY & $\begin{array}{l}\text { Current lack of knowledge transfer from experts to SMEs for the implementation of } 14.0 \\
\text { Lack of risk management tools for investments in new processes }\end{array}$ \\
\hline
\end{tabular}


with the ERP system or an underlying Manufacturing Execution System (MES) system in order to be able to exchange production data in real time.

Likewise, in the medium term SMEs should concern themselves with advanced manufacturing technologies. Technologies like high speed and high precision computer numerical control (CNC) machines, collaborative robots, or 3D printers are currently economically more feasible for SMEs.

In the long term, smaller companies will have to gradually deal with topics such as artificial intelligence and machine learning. Although the widespread use of these technologies in industrial practice will continue for some years to come, this change will also be mastered by those who adapt to it at an early stage.

Regarding the aforementioned limitations and barriers SMEs should decrease the cultural barriers by providing transparent implementation plans of Industry 4.0 in a mediumterm perspective. To improve the acceptance level, especially for top management and owners, Industry 4.0 technology providers should guarantee an appropriate data security level. Employees should be trained to appropriately plan and manage the implementation phase of Industry 4.0 technologies and concepts [Dallasega, 2018].

These are not easy goals to accomplish and will require a new mindset that SMEs, to remain competitive, are in urgent need to integrate the necessary technologies. Training programs and skills development are important organizational capabilities that require development. Policy makers who realize that SMEs are a backbone of most local and regional economies should seek to support investment and incentivize, maybe through tax breaks or other measures, supporting SME Industry 4.0 industrialization. It is not only good for the company, but many countries to make their industries more competitive.

Knowing the needs, capabilities, and barriers of for Industry 4.0 is important. These items summarized in this paper can inform companies, managers, and policy makers of many issues. Just their listing can provide some initial guidance for planning purposes.

\section{FURTHER CONSIDERATIONS AND CONCLUSION}

Bigger companies have advanced Industry 4.0 and SMEs are at risk to not fully exploit this potential for efficiency improvements and build their competitiveness. Even if SMEs have the potential to rapidly digitally transform their manufacturing more rapidly, the application of Industry 4.0 is still quite challenging.

The paper presents specific requirements, barriers and difficulties that were identified within workshops with SMEs from Europe (Italy and Austria), USA (Massachusetts) and Asia (Thailand).

The identified requirements were listed in specific clusters. The ones that received particular attention by participant included: 1) Agility in manufacturing and Mass Customization, 2) Real-time data, digitization and connectivity, 3 ) Advanced Manufacturing
Technologies and Automation, 4) Ease of Use and low Investment as well as 5) Machine Learning and Smart Data Analytics.

The following major barriers were highlighted: 1) Cultural barriers in terms of lack of acceptance of owners, managers and employees, 2) difficulties within the implementation phase, 3) scarcity of qualified staff and 4) the difficult assurance of an appropriate data security level. Based on the identified requirements, barriers and difficulties, we identified some recommendations for action by organizations and their managers from short, medium and long-term perspectives.

Future research consists of enhancing the validity and reliability of the presented results, by means of specific surveys and a statistical generalization to a broader population. Furthermore, specific models to assess the current level of Industry 4.0 as well as the technical and organizational readiness of SMEs will be developed and applied into practice.

These exploratory results should help SMEs and their stakeholders plan for technology that can provide them with long-term competitive advantages.

\section{ACKNOWLEDGMENT}

The authors would like to thank the Editor-in-Chief Prof. J. Sarkis for his kind invitation and comments for the development of this paper.

This paper is part of research activities in the project "SME 4.0 Industry 4.0 for SMEs". This work was supported by the European Union's Horizon 2020 Research and Innovation Program under the Marie Skłodowska-Curie Grant 734713. 


\section{REFERENCES}

Brusselsnetwork. (2018). Annual report 2018 on European SMEs.[Online]. Available: https://www.brusselsnetwork.be/ annual-report-2018-on-europeansmes/. Accessedon: Dec. 27, 2018.

Dallasega P. (Sep. 2018). Industry 4.0 fostering construction supply chain management: Lessons learned from engineer-to-order suppliers. IEEE Engineering Management Review, 46(3), 49-55, doi: 10.1109/ EMR.2018.2861389.

Dallasega P., Woschank M., Ramingwong S., Yaibuathet Tippayawong S., and Chonsawat N. (2019). Field study to identify requirements for smart logistics of European. in Proceedings of the International Conference on Industrial Engineering and Operations Management, Bangkok, Thailand, 844-855.

Eurostat 2018. 2018. Small and medium-sized enterprises: An overview. Annual report on European SMEs. Special Background Document on the internationalisation of SMEs. SME Performance Review 2017/2018.eurostat. 2018. [Online]. Available: https://ec.europa.eu/eurostat/web/products-eurostatnews/-/EDN-20181119-1. Accessed on: Dec. 3, 2019.

Madani, A. E. 2018. SME Securitization in SME Policy: Comparative analysis of SME definitions. International Journal of Academic Research in Business and Social Sciences, 8(8), 103-114, doi:10.6007/IJARBSS/v8-i8/4443.

Matt, D. T., Orzes, G., Rauch, E., and Dallasega P. (2018). Urban production-a socially sustainable factory concept to overcome shortcomings of qualified workers in smart SMEs. Computers \& Industrial Engineering, doi:10.1016/j. cie.2018.08.035.

Orzes, G., Rauch, E., Bednar, S., and Poklemba, R. 2018. Industry 4.0 implementation barriers in small and medium sized enterprises: A focus group study. in Proceeding 2018 IEEE International Conference on Industrial Engineering and Engineering Management, 1348-1352. [Online]. Available: https://doi.org/10.1109//EEM.2018.8607477.

Rauch E., Stecher T., Unterhofer M., Dallasega P., and Matt DT. (2019). Suitability of industry 4.0 concepts for small and medium sized enterprises: Comparison between an expert survey and a user survey (Best Track Paper Award). in Proceedings of the International Conference on Industrial Engineering and Operations Management, Bangkok, Thailand, pp. 11741185.

Rickmann, H. 2014. Verschläft der deutsche Mittelstand einen Megatrend? [Online]. Available: http://www.focus.de /finanzen /experten/rickmann/geringerdigitalisierungsgrad-verschlaeft-der-deutschemittelstand-einenmegatrend_id_3973075.html. Accessed on: Jan. 10, 2016.

SBA. 2018. Small business profile. [Online]. Available: https://www.sba.gov/sites/ default/files/advocacy/2018-Small-Business-Profiles-US.pdf. Accessed on: Jan. 12, 2019.

Ward. 2018. SME definition (Small to Medium Enterprise). [Online]. Available: https://www.thebalancesmb.com/sme-small-to-medium-enterprise-definition2947962. Accessed on: Mar. 13, 2019.

Erwin Rauch is an Assistant Professor for Manufacturing Technology and Systems with the Free University of Bolzano, Bolzano, Italy, where he is the Head of the Smart Mini Factory laboratory for Industry 4.0. He has 10 years of experience as a Consultant and later Associate Partner in an industrial consultancy firm operating in production and logistics. He is the Project Manager of the EU-funded H2020 research project "SME 4.0 -Industry 4.0 for SMEs" in an international partner 
consortium. His current research is on Industry 4.0, social sustainability in production, smart and sustainable production systems, smart shopfloor management and engineer/make to order. Furthermore, he is author and co-author of more than 130 scientific and non-scientific books, chapters of books, articles and other contributions and received several awards for scientific contributions.

Patrick Dallasega studied from the Free University of Bolzano, Bolzano, Italy and the Polytechnic University of Turin, Turin, Italy. He received the Ph.D. degree from the University of Stuttgart, Stuttgart, Germany. He is an Assistant Professor of Project Management and Industrial Plants Design with the Faculty of Science and Technology, Free University of Bolzano, Italy. He was Visiting Scholar with the Excellence Center in Logistics and Supply Chain Management, Chiang Mai University, Thailand and with the Worcester Polytechnic Institute, Massachusetts, USA. His main research interests are in, supply chain management, Industry 4.0, lean construction, lean manufacturing and production planning and control in MTO and ETO enterprises.

Marco Unterhofer received the industrial mechanical engineering from the Free University of Bolzano, Bolzano, Italy. He is currently working toward the Ph.D. degree with the Free University of Bolzano, Italy, and the University of Stuttgart, Stuttgart, Germany. His research interest is on the introduction of Industry 4.0 technologies in small and medium sized manufacturing companies and in hospitals. 